A. L. Moura ${ }^{1}$, C. Pereira ${ }^{1,2}$, F. S. Regateiro ${ }^{1,3}$, J. Azevedo ${ }^{1}$, A. TOdO BOM ${ }^{1,4}$, I. Carrapatoso ${ }^{1}$

\title{
Pru p 3 sublingual immunotherapy ultra-rush protocol is safe and clinically effective
}

\author{
${ }^{1}$ Allergy and Clinical Immunology Unit, Centro Hospitalar e Universitário de Coimbra, Coimbra, Portugal \\ ${ }^{2}$ Clinical Immunology, Faculty of Medicine, University of Coimbra, Portugal \\ ${ }^{3}$ Institute of Immunology, Faculty of Medicine, University of Coimbra, Portugal \\ ${ }^{4}$ Faculty of Medicine, University of Coimbra, Portugal
}

\section{KEYWORDS}

LTP syndrome; peach allergy; Pru $p$ 3; sublingual immunotherapy; ultra-rush protocol

\author{
Corresponding author \\ Ana Luísa Moura \\ Serviço de Imunoalergologia \\ Centro Hospitalar e Universitário de Coimbra \\ Praceta Prof. Mota Pinto, \\ 3000-075 Coimbra, Portugal \\ Phone: + 351239400400 \\ E-mail: al-moura@hotmail.com
}

Doi

10.23822/EurAnnACI.1764-1489.99

\begin{abstract}
Summary
Introduction. Sublingual immunotherapy (SLIT) with Pru $p 3$ can prevent severe allergic reactions to LTP-containing foods but the standard initiation protocol is time-consuming. Aim. Establish the safety of a novel ultra-rush initiation protocol for SLIT with Pru p 3. Methods. Prospective study comparing the side effects of the standard vs novel ultra-rush initiation protocols of SLIT with Pru $p$ 3 in patients with anaphylaxis to LTP. Results. Fifteen patients were included (standard initiation, 5; ultra-rush initiation, 10), 80\% females. All patients had oropharyngeal pruritus during initiation, $80 \%$ with spontaneous recovery, but no other gastro-intestinal, respiratory, cutaneous or systemic side effects occurred in any patient of both groups. Conclusion. The novel ultra-rush protocol halved the build-up time without increasing side effects.
\end{abstract}

\section{Introduction}

Lipid transfer protein (LTP) is a panallergen widespread throughout the plant kingdom and is a cause of allergic reactions to a large number of taxonomically unrelated plant foods $(1,2)$. LTP "syndrome" is typically described in adolescent and adult populations, and it is more frequent in the Mediterranean countries (14), with an increasing incidence in recent years (1). Co-factors, such as exercise, non-steroidal anti-inflammatory drugs, alcohol consumption and long fasting periods, can modulate clinical manifestations $(5,6$, 7, 8). Strict avoidance of LTP-containing foods is difficult to maintain and has a great impact in quality of life (9). Furthermore, avoidance does not seem to modify the natural course of the disease.

Specific allergen immunotherapy elicits a wide range of immunological mechanisms that allow tolerance to some foods (10,
12, 13). However, side effects are frequently observed, including anaphylaxis, particularly during the build-up phase (11). SLIT with peach extracts has been developed and is a disease-modifying treatment for LTP syndrome (16).

A peach LTP (Pru p 3) extract is commercially available (ALK, Spain. The manufacturer's standard initiation protocol has a duration of 4 days (Table I) $(15,16,17)$ and adverse reactions to this therapy largely occurred during this build-up phase. Most adverse events were mild oropharyngeal symptoms, easily controlled with antihistamines $(15,16)$. The 2009 Fernandez-Rivas et al. study was the first double-blind, placebo-controlled, randomized clinical trial assessing the safety and efficacy of SLIT with Pru p 3 (16). The treatment consisted of a build-up phase performed for five days (cumulative dose of $84.94 \mu \mathrm{g}$ of Pru p 3) followed by six months of three days per week administration of a maintenance dose at home (cumulative dose of $948 \mu \mathrm{g}$ of Pru p 3) (16). Eighty-two per- 
cent of the participants in the active group experienced local adverse reactions, nearly all located to the oropharynx, both in build-up and maintenance phases (16). Systemic reactions were recorded in $13.5 \%$ of patients $(87.5 \%$ of which occurred during the build-up phase) and included skin pruritus, skin erythema, urticaria, rhinoconjunctivitis, stomach pain and diarrhoea (16). No severe adverse events were observed (16). The 2015 Costa et al. study evaluated clinical and immunological parameters in patients that initiated SLIT with Pru $\mathrm{p}$ 3 (17). Initiation consisted in a 4-day build-up phase in Day Hospital followed by an outpatient maintenance phase of 3 years. Fifty percent of the patients had local reactions (itching) with spontaneous resolution during induction, and no other side effects on build-up or maintenance, confirming the safety of SLIT with Pru p 3 (17).

The manufacturer's standard protocol is time-consuming for both patient and medical staff. Pereira et al. (2009) described a novel ultra-rush protocol with a build-up phase completed in one day (18). The patient described had oral pruritus and paraesthesia of the tongue and lips during the first three doses but no treatment was required and maintenance dose was reached in one day (18). Daily SLIT treatment was safely completed during one year with no further symptoms and several immunological changes related to immunotherapy were observed (18).

The aim of our study was to compare the frequency and severity of side effects of the novel ultra-rush protocol versus the standard protocol, both during build-up and maintenance phases of Pru p 3 SLIT.

\section{Methods}

This retrospective study included patients with, at least, one episode of anaphylaxis after the ingestion of peach or other foods containing LTP and confirmed IgE-mediated sensitivity to Pru p 3, that initiated SLIT with Pru p 3 between the years 2012 and 2018. The inclusion criteria were: unequivocal clinical history of allergy to peach and/or other fruits containing LTP, one or more episodes of anaphylaxis following the ingestion of peach and/ or other fruits containing LTP, positive skin prick tests (SPT) to peach extract and/or other fruits containing LTP, positive SPT to Pru p 3, positive specific IgE to peach and Pru p 3.

The skin prick and prick-to-prick tests were performed according to the standardized European protocols (19), using commercialized extracts from ALK and Roxall-Aristegui or foods in nature, respectively. Tests were considered positive when wheals were equal or larger than 3 millimetres compared to the negative control.

Specific IgE measurements were conducted by ImmunoCAP specifications according to manufacturer's recommendations (Thermo Fisher Scientific, Sweden). Results higher than 0.35 $\mathrm{kU} / \mathrm{L}$ were considered positive.

Oral provocation tests (OPT) were not performed since all patients had anaphylactic episodes after the ingestion of food containing LTP in the previous two years and also declined a challenge that could induce a new anaphylaxis.

All patients or patient caregivers (in patients $<18$ years-old) signed an informed consent.

Table I. SLIT with Prup 3 - standard build-up phase protocol

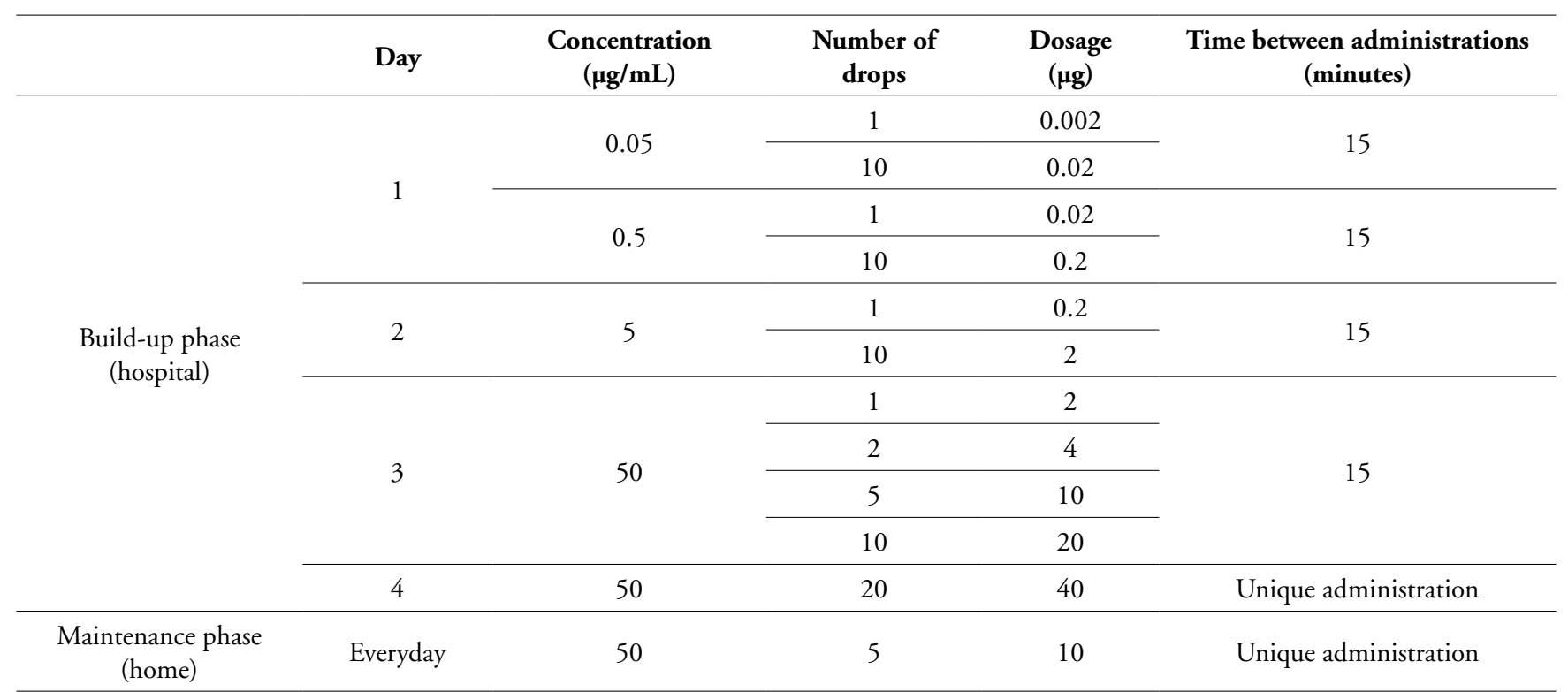


Immunotherapy to LTP used the commercialized extract of enriched peach with Pru p $3(50 \mu \mathrm{g} / \mathrm{mL})$ from ALK, Spain. The extract drops were administered sublingually after a fasting period of six hours, and kept under the tongue for two minutes before expelling.

Patients were divided in two different initiation protocols, Table I and Table II:

- Group A (5 patients): standard protocol, according to manufacturer's instructions, with a total duration of 4 days under medical supervision until maintenance dose;

- Group B (10 patients): novel ultra-rush protocol, as detailed in table II, and with a total duration of 2 days under medical supervision. The maintenance dose was reached in the first day with the ultra-rush protocol and the total duration was two days (table II).

The assignment to each protocol was performed in two manners: (1) a chronological way, with the first patients initiating with the standard protocol; and (2) according to the preferred method of the prescribing doctor. Both the chronology of patients' appointment and doctor's distribution of the patients at the first appointment were random.

The enriched extract $(50 \mu \mathrm{g} / \mathrm{mL})$ was diluted into three concentrations in the standard protocol $(5 \mu \mathrm{g} / \mathrm{mL}, 0.5 \mu \mathrm{g} / \mathrm{mL}$ and $0.05 \mu \mathrm{g} / \mathrm{mL}$ ) and two concentrations in the ultra-rush protocol $(5 \mu \mathrm{g} / \mathrm{mL}$ and $0.5 \mu \mathrm{g} / \mathrm{mL})$ for immunotherapy initiation and build-up phase.
In both protocols, patients were under permanent medical supervision during the initiation and any suspected adverse effects were promptly evaluated and treated when necessary.

At 12 months after SLIT initiation, patients were re-evaluated: adherence to the SLIT was confirmed, new episodes of contact with LTP containing foods were reviewed, SPT were performed, and sIgE to Pru p 3 and other relevant foods were measured.

Normality test, two-tailed Mann-Whitney U-test and Fisher Exact Test were calculated where appropriate using STATA (StataCorp. 2017. Stata Statistical Software: Release 15. College Station, TX: StataCorp LLC). The level of significance considered was $\alpha=0.05$.

All patients and/or guardians signed informed consent for the study.

\section{Results}

The study included fifteen patients with a confirmed diagnosis of IgE-mediated anaphylaxis to LTP that initiated SLIT to Pru p 3. Five patients underwent the standard SLIT initiation protocol (group A) and 10 patients initiated SLIT using the novel ultra-rush protocol (group B). The cumulative allergen doses in the build-up phase were different between the two groups, 47 $\mu \mathrm{g}$ in the ultra-rush protocol group and $78 \mu \mathrm{g}$ in the standard group, up to the daily maintenance dose of $10 \mu \mathrm{g}$ of Pru p 3 . Detailed demographic data, clinical aspects and allergy workup are shown in table III for both groups.

Table II. SLIT with Prup 3 - ultra-rush build-up phase protocol

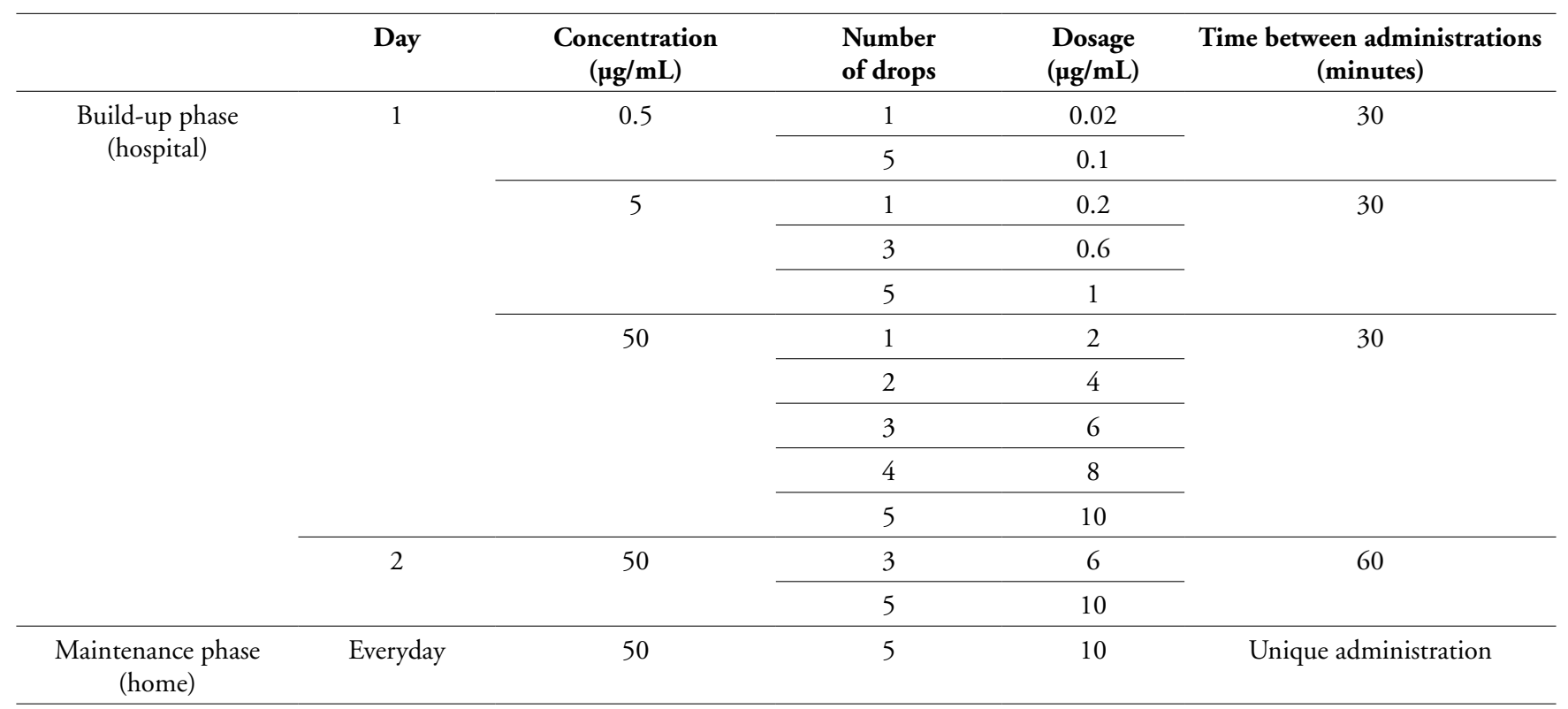


Most patients included in the study were females (80\%), with a median age of 23.4 years-old at the beginning of the treatment (minimum of 17, maximum of 35). Atopy was present in $73 \%$ of the patients, and rhinitis was the most concomitant diagnosis $(60 \%)$, followed by asthma (27\%) and atopic dermatitis (7\%). All patients had at least one episode of anaphylaxis, and peach was the most frequently implicated fruit $(5 / 15)$, followed by tomato $(3 / 15)$ and pear (2/15). Other culprit foods were plum, cherry, hazelnut, rice and fig (one patient each). Co-factors were present in 3 patients, namely exercise, NSAIDs intake and alcohol ingestion. All patients had positive SPT to commercial peach extract, with an average weal diameter of $7 \mathrm{~mm}$ (minimum of 3 , maximum of 11). The 8 patients submitted to prick-to-prick tests with skin and pulp of peach had positive results, with an average weal of 8 and $7 \mathrm{~mm}$, respectively. Prick-to-prick with peach was not performed in seven patients because of seasonal unavailability of the fruit. SPT with Pru p 3 extract was positive in eleven patients (average weal of $10 \mathrm{~mm}$ ), negative in two and not performed in two other patients (extract was out of stock).

The initial measurement of sIgE to peach and Pru $\mathrm{p} 3$ was positive in all patients, with an average concentration of $22.8 \mathrm{kU} / \mathrm{L}$ (minimum $1.13 \mathrm{kU} / \mathrm{L}$, maximum $>100 \mathrm{kU} / \mathrm{L}$ ) for peach and $22.3 \mathrm{kU} / \mathrm{L}$ (minimum of $1.69 \mathrm{kU} / \mathrm{L}$, maximum of $>100 \mathrm{kU} / \mathrm{L}$ ) for Pru p 3. Only one patient was monosensitized to peach, while the rest of the patients had polysensitization to other LTP-containing foods, as confirmed by sIgE.

Table III. Clinical and demographic data of patients that initiated standard protocol of SLIT with Pru p 3 (group A) and ultra-rush protocol of SLIT with Prup 3 (group B)

\begin{tabular}{|c|c|c|c|c|c|c|c|c|c|c|c|c|c|c|c|c|c|c|}
\hline $\begin{array}{l}\overline{8} \\
0 \\
0\end{array}$ & 苞 & ڤ્山 & 育 & 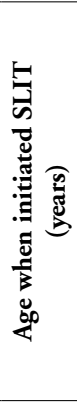 & 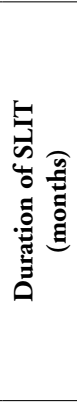 & 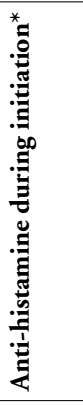 & 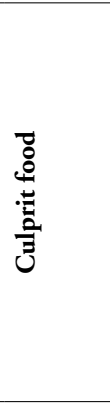 & 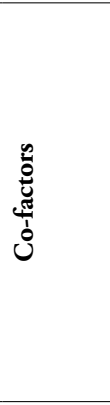 & 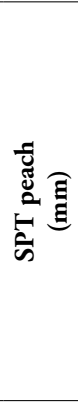 & 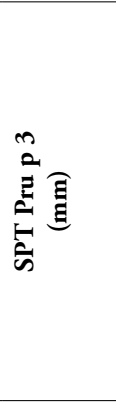 & 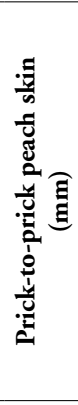 & 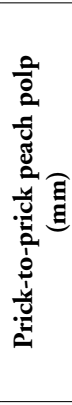 & 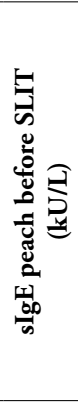 & 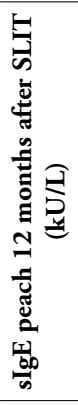 & 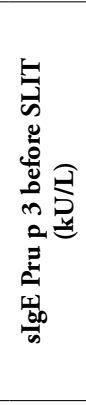 & 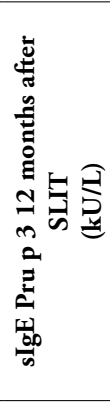 & 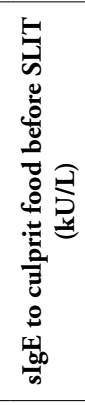 & 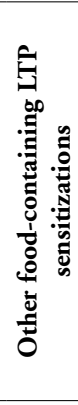 \\
\hline \multirow{5}{*}{ 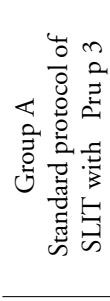 } & 1 & $\mathrm{~F}$ & $\begin{array}{l}\mathrm{R} \\
\mathrm{A}\end{array}$ & 26 & 40 & no & peach & no & 3 & 4 & 8 & 9 & 6.73 & 0.74 & 9.28 & 0.15 & 6.73 & yes \\
\hline & 2 & $\mathrm{~F}$ & $\begin{array}{c}\mathrm{R} \\
\mathrm{AE} \\
\end{array}$ & 26 & 12 & no & fig & no & 8 & ND & $\mathrm{ND}$ & ND & $>100$ & 50.1 & $>100$ & 61.5 & 1.41 & yes \\
\hline & 3 & $\mathrm{~F}$ & $\mathrm{~A}$ & 27 & 15 & no & tomato & no & 9 & 13 & $\mathrm{ND}$ & $\mathrm{ND}$ & 26.7 & 19.7 & 21.2 & 19.2 & 1.84 & yes \\
\hline & 4 & $\mathrm{~F}$ & A & 23 & 3 & no & pear & no & 7 & 9 & $\mathrm{ND}$ & ND & 10.2 & ND & 11 & ND & 6.61 & yes \\
\hline & 5 & $\mathrm{~F}$ & $\begin{array}{l}\mathrm{R} \\
\mathrm{A}\end{array}$ & 17 & 3 & no & pear & no & 6 & 12 & $\mathrm{ND}$ & ND & 1.75 & ND & 1.69 & 8.64 & 0.53 & yes \\
\hline \multirow{10}{*}{ 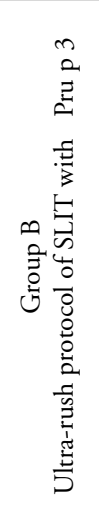 } & 1 & $\mathrm{~F}$ & $\mathrm{R}$ & 2 & 1 & $\mathrm{n}$ & peach & no & 8 & negative & 8 & 4 & 4.6 & 5.8 & 2.09 & 8.73 & 4.6 & yes \\
\hline & 2 & $\mathrm{~F}$ & no & 26 & 54 & no & plum & $\begin{array}{l}\text { exercise } \\
\text { alcohol }\end{array}$ & 6 & 10 & 5 & 4 & 4.3 & 2.2 & 2.77 & 1.84 & 0.92 & yes \\
\hline & 3 & $\mathrm{~F}$ & no & 27 & 46 & no & tomato & no & 6 & 6 & 5 & 7 & 19.3 & 6.2 & 19.9 & 8.9 & 2.1 & yes \\
\hline & 4 & $\mathrm{~F}$ & $\begin{array}{l}\mathrm{R} \\
\mathrm{A}\end{array}$ & 23 & 17 & no & cherry & exercise & 5 & 14 & 7 & 8 & 2.83 & 13.9 & 2.99 & 15.3 & 1.61 & yes \\
\hline & 5 & $\mathrm{~F}$ & no & 17 & 17 & no & hazelnut & no & (3) & 6 & 7 & 6 & 30.7 & 19.8 & 39.9 & 20 & 3.39 & yes \\
\hline & 6 & $\mathrm{M}$ & no & 35 & 15 & yes & rice & no & 4 & negative & 5 & 5 & 2.47 & 1.09 & 3.61 & 1.11 & 1.99 & yes \\
\hline & 7 & M & no & 22 & 16 & yes & tomato & $\begin{array}{l}\text { alcohol } \\
\text { NSAID }\end{array}$ & f & 6 & ND & ND & 49.1 & 53.3 & 41.3 & 69.5 & 14.2 & yes \\
\hline & 8 & M & $\begin{array}{l}\mathrm{R} \\
\mathrm{A}\end{array}$ & 19 & 10 & no & peach & exercise & 8 & 8 & ND & ND & 80.2 & ND & 84.7 & ND & 80.2 & yes \\
\hline & 9 & $\mathrm{~F}$ & $\mathrm{R}$ & 17 & 16 & no & peach & no & 8 & 8 & ND & ND & 1.13 & ND & 5.46 & $\mathrm{ND}$ & 1.13 & no \\
\hline & 10 & $\mathrm{~F}$ & $\mathrm{R}$ & 20 & 16 & no* & peach & no & 11 & ND & 12 & 12 & 3.96 & 1.36 & 3.84 & $\mathrm{ND}$ & 3.96 & yes \\
\hline
\end{tabular}

Legend: SLIT, sublingual immunotherapy; SPT, skin prick tests; OPC, oral provocation challenge; F, female; M, male; NSAID, non-steroidal anti-inflammatory drug; R, allergic rhinitis; A, bronchial asthma; AE, atopic eczema; mm, millimeters; ND, not done. For statistical analysis, when sIgE values were measured above detection limit of the technique $(>100 \mathrm{kU} / \mathrm{L})$, the value 100 was considered for calculations.

* Patient that initiated Pru p 3 SLIT with the standard protocol and switched to ultra-rush protocol after refractory oropharyngeal pruritus during standard build-up. 
Twelve months after SLIT initiation, sIgE concentrations to peach averaged $15.8 \mathrm{kU} / \mathrm{L}$, an average reduction of $7.0 \mathrm{kU} / \mathrm{L}$ (non-significant, $\mathrm{p}=0.1744$ ), having increased in three patients, all from the ultra-rush group, and decreased in eight patients. The average sIgE to Pru p 3 after 12 months of treatment was $20.3 \mathrm{kU} / \mathrm{L}$, an average decrease of $2 \mathrm{kU} / \mathrm{L}$ (non-significant, $\mathrm{p}=0.70$ ) with increased concentrations observed in four patients, three of which from the ultra-rush group.

During the build-up phase, all patients reported mild symptoms attributable to therapy (table IV). The symptoms were oropharyngeal pruritus and tongue paraesthesia.

One patient started the immunotherapy with the standard protocol but was switched to the ultra-rush protocol (and for analysis she was included in this group). On the first day of the induction using the standard protocol, she developed oropharyngeal pruritus refractory to anti-histamine treatment and required additional doses of treatment. Two hours after complete resolution of the symptoms, SLIT treatment was reinitiated using the ultra-rush protocol without any symptoms during the rest of the build-up phase. Anti-histamine was administered in two patients from the ultra-rush group, both with rapid resolution of symptoms and both continued the induction with no further symptoms.

All the remaining patients from both groups had mild oropharyngeal pruritus during the first three doses of the administration of the extract without requiring any relieve medication, and proceeded with good tolerance to the following doses, having continued and completed the protocol with no further symp-

Table IV. Description of duration of Pru $\mathrm{p} 3$ SLIT and side effects

\begin{tabular}{|c|c|c|c|c|}
\hline & Total population & $\begin{array}{l}\text { Standard protocol } \\
\text { group }\end{array}$ & $\begin{array}{l}\text { Ultra-rush protocol } \\
\text { group }\end{array}$ & $\begin{array}{c}\text { Difference between } \\
\text { treatment groups }\end{array}$ \\
\hline Number of patients & 15 & 5 & 10 & - \\
\hline Age (median, mean, min., max.) (years) & $22,23,17,35$ & $22,23,17,33$ & $20,23,17,35$ & $\begin{array}{l}\text { Mean: NS } \\
\mathrm{p}=0.667\end{array}$ \\
\hline Female $(\mathrm{n}, \%)$ & $12,80 \%$ & $5,100 \%$ & $7,70 \%$ & \\
\hline Duration of the initiation phase (days) & - & 4 & 2 & - \\
\hline $\begin{array}{l}\text { Duration of treatment } \\
\text { (median, mean, min., max.) (months) }\end{array}$ & $16,20,3,54$ & $12,15,3,40$ & $16,22,10,54$ & $\begin{array}{c}\text { Mean: NS } \\
\mathrm{p}=0.112\end{array}$ \\
\hline $\begin{array}{l}\text { Number of patients with side effects during } \\
\text { initiation }(\mathrm{n}, \%)\end{array}$ & $15,100 \%$ & $6,100 \% *$ & $10,100 \%$ & - \\
\hline $\begin{array}{l}\text { Number of patients requiring medication for } \\
\text { side effects during initiation }(\mathrm{n}, \%)\end{array}$ & $3,20 \%$ & $1,16.7 \% *$ & $2,20 \%$ & $\begin{array}{c}\mathrm{NS} \\
\mathrm{p}=1.000\end{array}$ \\
\hline $\begin{array}{l}\text { Number of patients with side effects during } \\
\text { maintenance }\end{array}$ & 0 & 0 & 0 & - \\
\hline $\begin{array}{l}\text { Number of patients requiring medication for } \\
\text { side effects during maintenance }\end{array}$ & 0 & 0 & 0 & - \\
\hline sIgE peach before SLIT (average) (kU/L) & 22.9 & 29 & 19.9 & $\begin{array}{c}\mathrm{NS} \\
\mathrm{P}=0.582\end{array}$ \\
\hline $\begin{array}{l}\text { sIgE peach after } 1 \text { year of treatment (average) } \\
(\mathrm{kU} / \mathrm{L})\end{array}$ & 15.8 & 23.5 & 13 & $\mathrm{NA}^{* *}$ \\
\hline $\begin{array}{l}\text { Average difference in sIgE peach before vs } \\
\text { after } 1 \text { year of treatment }(\mathrm{kU} / \mathrm{L})\end{array}$ & $\begin{array}{c}-7.1 \\
N S, p=0.603\end{array}$ & $\begin{array}{l}-5.5 \\
\mathrm{NA}^{* *}\end{array}$ & $\begin{array}{c}-6.9 \\
\text { NS, } p=0.757\end{array}$ & $\mathrm{NA}^{* *}$ \\
\hline sIgE Pru p 3 before SLIT (average) (kU/L) & 23.3 & 28.7 & 20.7 & NS, $\mathrm{p}=0.667$ \\
\hline $\begin{array}{l}\text { sIgE Pru p } 3 \text { after } 1 \text { year of treatment } \\
\text { (average) }(\mathrm{kU} / \mathrm{L})\end{array}$ & 20.5 & 22.4 & 19.1 & $\mathrm{NA}^{* *}$ \\
\hline $\begin{array}{l}\text { Average difference in sIgE Pru p } 3 \text { before vs } \\
\text { after } 1 \text { year of treatment }(\mathrm{kU} / \mathrm{L})\end{array}$ & $\begin{aligned}-2.8 \\
\text { NS, } p=0.795\end{aligned}$ & $\begin{array}{l}-6.3 \\
\mathrm{NA}^{* *}\end{array}$ & $\begin{array}{c}-1.6 \\
N S, p=0.960\end{array}$ & $\mathrm{NA}^{* *}$ \\
\hline
\end{tabular}

Legend: NA, non-applicable

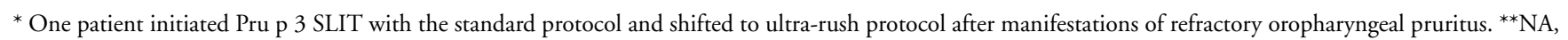
not applicable (when groups had less than 5 samples, continuous variable statistics were not calculated). 
toms. No systemic side effects were observed during the buildup phase in any patient. No patients reported additional side effects during the maintenance doses administrated at home (duration of treatment described below).

At the moment, 8 patients are currently on SLIT treatment, having completed a median of 24 months (minimum of 10 , maximum of 54), all from the ultra-rush protocol group (table IV). On the standard protocol group all patients interrupted SLIT: one patient decided to interrupt the treatment herself after completing 40 months of immunotherapy; another patient also decided herself to stop the SLIT when she found she was pregnant; a third patient had to interrupt because SLIT was temporarily unavailable in the market; the other two patients interrupted due to the high costs of the treatment. In total, 4 patients interrupted the treatment for economic reasons, two from each group, with an average treatment duration of 10 months. No additional side effects were reported during the maintenance doses taken at home.

One of the patients that completed 40 months of immunotherapy (with the standard protocol initiation) reported an episode of urticaria during exercise after the ingestion of apple with skin occurring one year after stopping treatment. There were no new episodes of anaphylaxis reported by any patient.

\section{Discussion}

In our case series, both the standard and the novel ultra-rush protocols for the initiation of SLIT with Pru p 3 were safe and well-tolerated. In both groups, the symptoms reported during the build-up phase were mild and localized to the oropharynx, with spontaneous resolution in the majority of cases. The patient with the most severe secondary effects started the SLIT according to the standard protocol, but had complete relieve after the administration of two rounds of anti-histamine treatment. The medical staff decided to change the build-up protocol to the ultra-rush, which was better tolerated and completed without further symptoms. The decision to change for the ultra-rush protocol was based on previous experience with the ultra-rush protocol patients and also taking into consideration well-known mechanisms of sub-lingual immunotherapy (19). Only two other patients needed anti-histamine for mild pruritus of the mouth and lips, but also continued the build-up protocol and reached maintenance dose with success after recovery. In addition, no systemic side effects were observed during the build-up and maintenance phases, emphasizing the good tolerance to this treatment. The novel ultra-rush protocol here proposed corresponds to a reduction to half the time when compared to the standard protocol, abbreviating the inconvenience for both patient and medical staff.

Specific IgE to peach and Pru p 3 was reduced (albeit not statistically significant, possibly due to small group size) and there were no clinical reactions to LTP containing foods (no new episodes of anaphylaxis after the ingestion of LTP-containing foods were reported by any patient after SLIT initiation). Taking into consideration the short length of the build-up phase ( 2 or 4 days) in the total duration of SLIT treatment, we do not predict any differences in efficacy between groups.

The most common culprit food in our cohort was peach, in accordance to what has been described for the Mediterranean area. Nevertheless, eight other LTP containing foods were responsible for the anaphylaxis in the two groups, once again demonstrating the variability of foods implicated in LTP syndrome.

In Portugal, specific immunotherapy with allergens is not subsidized by the national health system. SLIT with Pru p 3 is an expensive treatment, with an approximate cost of 1000 euros per year, and it is entirely supported by the patients. This is a limitation in terms of adherence that we could observe in our cohort.

In terms of limitations of this study, we point the small sample, in part caused by the costly access to this therapy. Only a few studies have been published describing SLIT to Pru p 3 and randomized double-blind controlled trials with larger samples are required to assess efficacy.

One patient from the standard protocol group that was on the twelfth month of treatment, decided herself to interrupt the treatment when she found out that she was pregnant. This was in contradiction to medical recommendations, since she was on maintenance doses which is not a contraindication to the continuation of the immunotherapy in pregnancy.

\section{Conclusions}

SLIT with Pru p 3 is a safe treatment for patients with LTP syndrome, including for those with severe manifestations, such as anaphylaxis. The ultra-rush build-up protocol here presented requires two days of medical supervision, which is more convenient than the four days expected with the standard build-up schedule. Our study demonstrates that this novel protocol is safe and well tolerated.

\section{Conflicts of interest}

The authors declare that they have no conflict of interests

\section{References}

1. Asero R, Piantanida M, Pinter E, Pravettoni V. The clinical relevance of lipid transfer protein. Clin Exp Allergy 2018; 48:6-12.

2. Asero R, Pravettoni V. Anaphylaxis to plant foods and pollen allergens in patients with lipid transfer protein syndrome. Curr Opin Allergy Clin Immunol 2013; 13:379-85.

3. Faber MA, Van Gasse AL, Decuyper II, et al. IgE-reactivity profiles to nonspecific lipid transfer proteins in a northwestern European country. J Allergy Clin Immunol 2017; 139:679-82. 
4. Mothes-Luksch N, Raith M, Stingl G, et al. Pru p 3, a marker allergen for lipid transfer protein sensitization also in Central Europe. Allergy 2017; 72:1415-18.

5. Cardona V, Luengo O, Garriga T, et al. Co-factor-enhanced food allergy. Allergy 2012; 67:1316-18.

6. Pascal M, Muñoz-Cano R, Reina Z, et al. Lipid transfer protein syndrome: clinical pattern, cofactor effect and profile of molecular sensitization to plant-foods and pollens. Clin Exp Allergy 2012; 42:1529-39.

7. Romano A, Scala E, Rumi G, et al. Lipid transfer proteins: the most frequent sensitizer in Italian subjects with food-dependent exercise induced anaphylaxis. Clin Exp Allergy 2012; 42:1643-53.

8. Arena A. Anaphylaxis to apple: is fasting a risk factor for LTP-allergic patients? Eur Ann Allergy Clin Immunol 2010; 42:155-58.

9. Muraro A, Werfel T, Hoffmann-Sommergruber K, et al. EAACI food allergy and anaphylaxis guidelines: diagnosis and management of food allergy. Allergy 2014; 69(8):1008-25.

10. Jutel, M, Agache, I, Bonini, S, et al. International consensus on allergy immunotherapy. J Allergy Clin Immunol 2015: 136(3), 556-68.

11. Begin P, Chinthrajah RS, Nadeau KC. Oral immunotherapy for the treatment of food allergy. Human Vaccines \& Immunotherapeutics 2014; 10(8):2295-302.

12. Pajno GB, Fernandez-Rivas M, Arasi S, et al. EAACI Guidelines on allergen immunotherapy: IgE-mediated food allergy. Allergy 2018; 73(4):799-815.
13. Graham F, Tardio N, Paradis L, et al. Update on oral immunotherapy for egg allergy. Hum Vaccin Immunother 2017; 13(10):245261.

14. Pascal M, Vazquez-Ortiz M, Folque MM, et al. Asymptomatic LTP sensitization is common in plant-food allergic children from the Northeast of Spain. Allergol Immunopathol 2016; 44:351-58.

15. Gomez F, Bogas G, Gonzalez M, et al. The clinical and immunological effects of Pru p 3 sublingual immunotherapy on peach and peanut allergy in patients with systemic reactions. Clin Exp Allergy 2017; 47:339-50.

16. Fernandez Rivas M, Garrido Fernandez S, Nadal JA, et al. Randomized double blind, placebo controlled trial of sublingual immunotherapy with a Pru p 3 quantified peach extract. Allergy 2009; 64(6): 876-83.

17. Costa AC, Melo A, Duarte F, et al. Efficacy and tolerance of sublingual immunotherapy with Pru p 3 in patients with peach severe allergy - clinical and immunological follow-up during 12 months. Rev Port Imunoalergologia 2015; 23(1):11-19.

18. Pereira C, Bartolome B, Asturias JA, et al. Specific sublingual immunotherapy with peach LTP (Pru p 3). One year treatment: a case report. Cases J 2009; 2(1), 6553.

19. Muraro A, Werfel T, Hoffmann-Sommergruber K, et al. EAACI food allergy and anaphylaxis guidelines: diagnosis and management of food allergy. Allergy 2014; 69(8):1008-25.

20. Pereira $C$ (Ed.). Specific Immunotherapy and Central Immune System, Allergic Diseases - Highlights in the Clinic, Mechanisms and Treatment. InTech, 2012: 375-402. 